\title{
The Veterans Affairs Patient Safety Center of Inquiry-Suicide Prevention Collaborative: Creating Novel Approaches to Suicide Prevention Among Veterans Receiving Community Services
}

\author{
Bryann DeBeer, PhD; Sylvia Baack, PhD, RN; Kathryn Bongiovanni, LCSW; Elisa Borah, PhD; Craig Bryan, PsyD; \\ Kattina Bryant, LCSW; Ruth Cassidy, LCSW, MDiv; Stephanie Clafferty, LCSW; Germaine Franciosi, RN; \\ Jenna Heise, MA; Claire Hoffmire, PhD; Robin Keene, PhD, RN; Joseph Mignogna, PhD; Nathaniel Mohatt, PhD; \\ Lindsey L. Monteith, PhD; Alan Peterson, PhD; Dawn Pierson, MS; Edgar Villarreal, PhD; Kimberly Weinberg, LCSW-S; \\ Marjory Williams, PhD, RN; Samantha Synett, LCSW; and Justin Benzer, PhD
}

\begin{abstract}
Background: While the US Department of Veterans Affairs has made significant strides to prevent veteran suicide, efforts have largely targeted veterans actively engaged in and eligible for Veterans Health Administration (VHA) care, which is consistent with the VHA mission. The majority of veterans are not enrolled in VHA care, and many are ineligible for services. Veterans not connected to VHA have experienced an increase in suicides in recent years.
\end{abstract}

Observations: Since 2018, VHA National Center for Patient Safety has funded the Patient Safety Center of Inquiry-Suicide Prevention Collaborative (PSCl-SPC), which has worked to develop, implement, and evaluate practical solutions aimed at curbing the rising suicide rate among veterans not receiving VHA care. PSCl-SPC has 3 guiding objectives: (1) Develop and test a collaborative, organizational structure to connect VHA and community organizations, such as national, local, public, private, nonprofit, and academic partners who provide high-quality and timely health care; (2) Build and test a learning collaborative to facilitate sharing of VHA suicide prevention best practices with community partners to increase availability, consistency, and quality of mental health services for all veterans; and (3) Implement, test, and refine a novel program to provide affordable suicide prevention interventions to veterans with mental health needs, regardless of their use of, or eligibility for, VHA services. This paper details the current progress for this demonstration project. As these objectives are met, PSCI-SPC will create and disseminate products to support broad implementation of these practices to other VA medical centers and the communities they are embedded in.

Conclusions: PSCI-SPC seeks to fill an important gap in veteran health care by serving as a national clinical innovation and dissemination center for best practices in suicide prevention for veterans who receive care in their communities.
Author affiliations can be found at the end article. Correspondence: Bryann DeBeer (bryann.debeer@va.gov)

Fed Pract. 2020;37(11):512-521. doi:10.12788/fp.0071 ince 2008, suicide has ranked as the tenth leading cause of death for all ages in the US, with rates of suicide continuing to rise. ${ }^{1-3}$ Suicide is even more urgent to address in veteran populations. The age- and sex-adjusted suicide rate in 2017 was more than 1.5 times greater for veterans than it was for nonveteran adults. ${ }^{2}$ Of importance, rates of suicide are increasing at a faster rate in veterans who are not connected to Veterans Health Administration (VHA) care. ${ }^{4,5}$ These at-risk veterans include individuals who are eligible for VHA care yet have not had a VHA appointment within the year before death; veterans who may be ineligible to receive VHA care due to complex rules set by legislation; and veterans who are eligible but not enrolled in VHA care. Notably, between 2005 and 2016, the number of veterans not enrolled in VHA care rose more quickly than did the number of veterans enrolled in VHA care..$^{5,6}$ Thus, to impact the high veteran suicide rates, an emergent challenge for VHA is to prevent suicide among unenrolled veterans and veterans receiving community care, while continuing to increase access to mental health services for veterans enrolled in VHA health care.

In response to the high rates of veteran suicide deaths, the US Department of Veterans Affairs (VA) has developed a broad, multicomponent suicide prevention program that is unparalleled in private US health care systems. ${ }^{4,7}$ Suicide prevention efforts are led and implemented by both the VHA National Center for Patient Safety and the VHA Office of Mental Health and Suicide Prevention. Program components are numerous and multifaceted, falling within the broad promotion and prevention strategies outlined by the National Academy of Medicine (NAM)., ${ }^{1,8-11}$ The NAM continuum of prevention model encompassing multiple strategies is also referred to as the Universal, Selective, Indicated (USI) 
TABLE 1 Universal, Selective, Indicated Model and Examples of Veterans Health Administration Suicide Prevention Programs

\begin{tabular}{|c|c|c|}
\hline Prevention Types & Definitions & Program Examples \\
\hline Promotion & $\begin{array}{l}\text { Targets the general public or whole population and aims } \\
\text { to promote mental health and enhance an individuals' } \\
\text { ability to achieve well-being. }\end{array}$ & $\begin{array}{l}\text { Positive coping skills education }{ }^{41-43} \\
\text { Military culture competency training for care } \\
\text { providers }\end{array}$ \\
\hline Universal & $\begin{array}{l}\text { Applied to the general population and includes proactive } \\
\text { awareness and education on suicide prevention resources } \\
\text { and eliminates the stigma of being associated with mental } \\
\text { health services. }\end{array}$ & $\begin{array}{l}\text { Predictive analytics and outreach (ie, REACH Vet) } \\
\text { Collaborative partnerships (eg, between Veterans Health } \\
\text { Administration and National Shooting Sports } \\
\text { Foundation) })^{1,41,43,46} \\
\text { Training for all staff }{ }^{141,43,47}\end{array}$ \\
\hline Selective & $\begin{array}{l}\text { Targeted at individuals or subgroups, based on biological } \\
\text { or social risk factors, whose suicide risk is higher than } \\
\text { average. }\end{array}$ & $\begin{array}{l}\text { Implementing evidence-based interventions for } \\
\text { co-occurring mental health disorders }{ }^{43,48-50} \\
\text { Offering nontraditional operating hours (ie, convenient care) }{ }^{7}\end{array}$ \\
\hline Indicated & $\begin{array}{l}\text { Aimed at individuals who are considered at higher risk } \\
\text { due to a prior suicide attempt or current suicide ideation, } \\
\text { but whose symptoms are not yet severe or prolonged } \\
\text { enough to meet diagnostic criteria. }\end{array}$ & $\begin{array}{l}\text { Implementing safety planning }{ }^{1,43,51,52} \\
\text { Flagging in the medical record or other record } \\
\text { systems } \mathbf{s}^{1,50}\end{array}$ \\
\hline
\end{tabular}

Model. ${ }^{7,8,10}$ The VHA suicide prevention program contains a wide spread of program components, making it both comprehensive and innovative (Table 1).

Although significant momentum and progress has been made within the VHA, policy set by legislation has historically limited access to VHA health care services to VHAeligible veterans. This is particularly concerning given the rising suicide rates among veterans not engaged in VHA care. ${ }^{2}$ Adding to this complexity, recent legislation has increased veterans' access to non-VHA health care, in addition to their existing access through Medicare, Medicaid, and other health care programs. ${ }^{12-14}$ Best practices for suicide prevention are not often implemented in the private sector; thus, these systems are ill prepared to adequately meet the suicide prevention care needs of veterans. ${ }^{4,15-18}$ Furthermore, VHA and non-VHA services generally are not well coordinated, and private sector health care providers (HCPs) are not required to complete a commensurate level of suicide prevention training as are VHA HCPs. ${ }^{16-18}$ Most non-VHA HCPs do not receive military cultural competence training. ${ }^{19}$ These issues create a significant gap in suicide prevention services and may contribute to the increases in suicide rates in veterans who do not receive VHA care. Thus, changes in policy to increase access through private sector care may have paradoxical effects on veteran suicide deaths. To impact the veteran suicide rate, VHA must develop and disseminate best practices for veterans who use non-VHA services.

\section{A Roadmap to Suicide Prevention}

There is significant momentum at the federal level regarding this issue. The President's Roadmap to Empower Veterans and End the National Tragedy of Suicide (Executive Order 13,861) directs the VHA to work closely with community organizations to improve veteran suicide prevention. ${ }^{20}$ The VHA and partners, such as the Substance Abuse and Mental Health Services Administration (SAMHSA), are bridging this gap with collaborative efforts that increase suicide prevention resources for veterans living in the community through programs such as the Governor's Challenges to Prevent Suicide Among Service Members, Veterans, and their Families. These programs intend to empower communities to develop statewide, strategic action plans to prevent veteran suicide. ${ }^{7,21-24}$

In addition to partnerships, VHA has built other aspects of outreach and intervention into its programming. A key VHA initiative is to "know all veterans" by committing to identifying and reaching out to all veterans who may be at risk for suicide. ${ }^{22}$ The VHA has committed to offering "emergency stabilization care for former service members who present at the facility with an emergent mental health need" regardless of eligibility. ${ }^{25}$ The intent is to provide temporary emergent mental health care to veterans who are otherwise ineligible for care, such as those who were discharged under other-than-honorable conditions while the VHA determines eligibility status. ${ }^{26}$ However, veterans must meet certain criteria, and there is a limit on services. 
Although services are being expanded to reach veterans who do not access VHA health care, how to best implement these new directives with regard to suicide prevention is unclear. Strategic development and innovations to expand suicide prevention care to veterans outside the current reach of VHA are desperately needed.

\section{PROGRAM OVERVIEW}

VHA Patient Safety Center of Inquiry-Suicide Prevention Collaborative (PSCI-SPC), funded by the VHA National Center for Patient Safety, aims to help fill the gap in community-based suicide prevention for veterans. PSCI-SPC is located within the VHA Rocky Mountain Mental Illness Research, Education, and Clinical Center in Aurora, Colorado. The overarching mission of PSCI-SPC is to develop, implement, and evaluate practical solutions to reduce suicide among veterans not receiving VHA care. PSCI-SPC serves as a national clinical innovation and dissemination center for best practices in suicide prevention for organizations that serve veterans who receive care in the community. PSCI-SPC creates products to support dissemination of these practices to other VAMCs and works to ensure these programs are sustainable. PSCI-SPC focuses on 3 primary objectives. All PSCI-SPC projects are currently underway.

\section{Objective 1: Growing a Community Learning Collaborative}

Acknowledging that nearly two-thirds of veterans who die by suicide do not use VHA services, PSCI-SPC aims to reduce suicide among all veterans by expanding the reach of best practices for suicide prevention to veterans who receive myriad services in the community. ${ }^{27}$ Community organizations are defined here as organizations that may in some way serve, interact with, or work with veterans, and/or employ veterans. Examples include non-VHA health care systems, public services such as police and fire departments, nonprofit organizations, mental health clinics, and veterans' courts. As veterans increasingly seek health care and other services within their communities, the success of suicide prevention will be influenced by the capability of non-VHA public and private organizations. Objective 1, therefore, seeks to develop a VHA-community collaborative that can be leveraged to improve systems of suicide prevention.

Current programs in the VHA have focused on implementation of suicide prevention awareness and prevention education campaigns instead of grassroots partnerships that are intended to be sustainable. Additionally, these programs typically lack the capacity and systems to sustain numerous meaningful community partnerships. Traditionally, community organizations have been hesitant to partner with government agencies, such as the VHA, due to histories of institutional mistrust and bureaucracy. ${ }^{28}$

The PSCI-SPC model for developing a VHA-community collaborative partnership draws from the tradition of communitybased participatory research. The best community-based participatory research practices are to build on strengths and resources within the local community; develop collaborative, equitable partnerships that involve an empowering and powersharing process; foster colearning, heuristics, and capacity building among partners; and focus on systems development using an iterative process. These practices also are consistent with the literature on learning collaboratives. ${ }^{29-31}$

The premise for a learning collaborative is to bridge the gap between knowledge and practice in health care. ${ }^{31}$ Figure 1 depicts how this collaborative was developed, and how it supports Objectives 2 and 3. To achieve Objective 1, we developed a VHA-learning collaborative of 13 influential community partners in the Denver and Colorado Springs region of Colorado. The VHA team consists of a learning collaborative leader, a program manager, and a program support assistant. The principal investigator attends and contributes to all meetings. Learning collaborative partners include a university psychology clinic that focuses on veterans' care, 3 veterans service organizations, a mental health private practice, a university school of nursing, a community mental health center, veterans' courts, and 5 city departments.

These partners participated in qualitative interviews to identify where gaps and breakdowns were occurring. With this information, the PSCI-SPC team and VHAlearning collaborative held a kickoff event. At this meeting the team discussed the qualita- 
FIGURE 1 Logic Model of Patient Safety Center of Inquiry-Suicide Prevention Collaborative

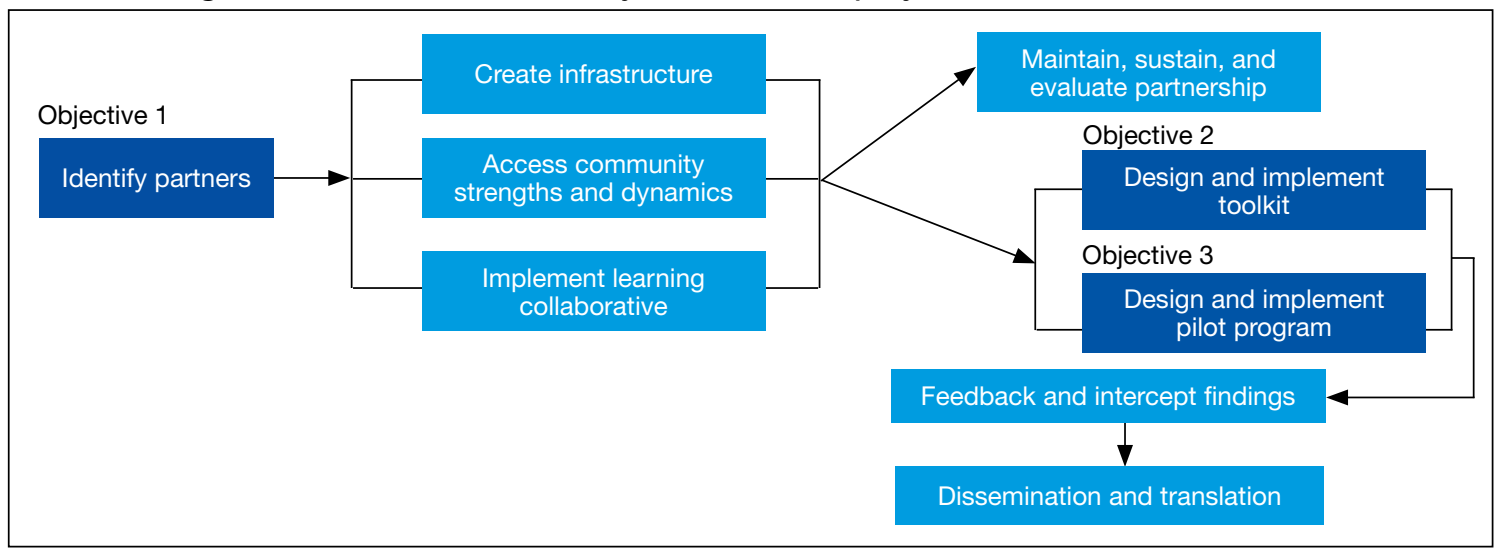

tive findings, provided veteran suicide prevention information, and basic information regarding suicide prevention program building and implementation science.

Throughout quarterly learning collaborative meetings and monthly facilitation calls, we have worked to develop a blueprint and an action plan for each partner to develop best practices for dissemination to aid in providing consistency in the standard of care. A postimplementation event will be held to identify successes and challenges encountered while operationalizing project action plans.

Currently, activities of the learning collaborative are making a large impact on the community. Not all collaborative members track information regarding their populations served, nor specific metrics on veterans encountered. Even so, of those who do capture metrics, suicide prevention program components implemented by the collaborative will impact more than 21,000 individuals and at least 2,500 known veterans. In addition, 52 new connections have been made between community organizations or between community organizations and the VHA, and $>300$ individuals have been trained.

The learning collaborative support team has assisted in the dissemination of a large resource list for veterans. As the learning collaborative is ongoing and we are working with organizations to improve their data collection and analytics, we expect these numbers to increase. We anticipate that the learning collaborative will develop a stronger suicide prevention safety net within the community. In addition, we expect increased referrals of at-risk veterans to the VHA and enhance the long-term continuity of care between community and VHA services.

\section{Objective 2: Implementation Toolkit}

The second PSCI-SPC objective is to develop a toolkit for the implementation of best practices within a VHA-community suicide prevention learning collaborative. Lessons from the development of a successful suicide prevention learning collaborative will be shared through an online guide that other VHA facilities can use to support similar collaborative efforts within their communities. The toolkit will be disseminated across the VHA to assist suicide prevention coordinators and other staff in developing a suicide prevention learning collaborative at their facilities.

PSCI-SPC uses the Zero Suicide framework and the VA/US Department of Defense (DoD) Clinical Practice Guideline for the Assessment and Management of Patients at Risk for Suicide as models for preventing suicide in veterans not enrolled in VHA care. ${ }^{11,32}$ This implementation toolkit focuses on how to implement suicide prevention best practices into organizations that serve veterans. This toolkit differs from clinical practice guidelines in that it focuses on implementation strategies to promote success and effectively address challenges.

In order to provide a menu of available options for the learning collaborative and resulting toolkit, PSCI-SPC uses a logic model to compare the components of the VHA suicide prevention program, as well as other similar veteran and military suicide prevention programs. ${ }^{71,12,14,21,33,34}$ These 
TABLE 2 Classification of SAMHSA Prevention Strategies

\begin{tabular}{|c|c|c|}
\hline Strategies & Definition & VHA Program Examples \\
\hline Information dissemination & $\begin{array}{l}\text { Increases knowledge and change attitudes through } \\
\text { communication }\end{array}$ & $\begin{array}{l}\text { Promotional materials for suicide prevention } \\
\text { information }\end{array}$ \\
\hline Prevention education & $\begin{array}{l}\text { Teaches important skills in preventing the } \\
\text { development of the targeted behavior }\end{array}$ & $\begin{array}{l}\text { Training staff in core competencies } \\
\text { of suicide prevention }\end{array}$ \\
\hline Positive alternatives & $\begin{array}{l}\text { Provides structured activities to promote constructive } \\
\text { ways to learn new skills }\end{array}$ & Promote connectedness \\
\hline Environmental strategies & $\begin{array}{l}\text { Changes policies where people work or live to reduce } \\
\text { risk factors and increase protective factors }\end{array}$ & $\begin{array}{l}\text { Implement a suicide prevention quality } \\
\text { improvement program }\end{array}$ \\
\hline Community-based processes & Work that strengthens the community's safety net & Developing a collaborative partnership \\
\hline $\begin{array}{l}\text { Identification of problems } \\
\text { and referral to services }\end{array}$ & $\begin{array}{l}\text { Determines whether individuals at high risk } \\
\text { require intensive interventions }\end{array}$ & Addressing co-occurring mental health conditions \\
\hline
\end{tabular}

Abbreviations: SAMHSA, Substance Abuse and Mental Health Services Administration; VHA, Veterans Health Administration. Adapted from Substance Abuse and Mental Health Services Administration. Focus on Prevention. https://store .samhsa.gov/product/Focus-on-Prevention/sma10-4120. Published March 2017. Accessed October 13, 2020.

programs are categorized into 2 types of prevention frameworks, the USI model as described above, and the SAMHSA Strategic Prevention Framework (Table 2). ${ }^{35}$ The SAMHSA framework was designed to promote mental health and prevent substance abuse, yet the derived classification is also applicable to suicide prevention programs..$^{35}$ The results of the logic model comparison form the basis of the best practice interventions for the learning collaborative and initial toolkit. In addition to the best practice interventions, the toolkit consists of documents describing how to develop a veteran suicide prevention learning collaborative, as well as tools for learning collaborative members. Current tool development includes workbooks to guide collaborative members through the implementation process, guides for community organizations in implementing suicide prevention screening and risk assessment, a standard operating procedure for suicide prevention in a veterans court, and peer support training for veteran suicide prevention.

The methods to achieve Objective 2 include regular discussions with the VHAlearning collaborative on current best practices, identifying gaps and overlap of community programs. Successes and challenges of implementing suicide prevention best practices into learning collaborative organizations will be documented and incorporated into the toolkit. The learning collaborative will work iteratively as a team to improve the toolkit. Once complete, the toolkit will be disseminated to other VHA health care systems nationally, as well as to other state or regional partners that the learning collaborative identifies. A plan is under development for national suicide prevention entities to also disseminate the toolkit to lessen the burden of veteran suicide through their stakeholder base.

\section{Objective 3: High-Risk Veterans Not Receiving VHA Care}

Although veterans not receiving VHA care account for a number of veteran deaths by suicide, we are not aware of any current VHA programs that provide temporary psychotherapy and intensive case management to at-risk veterans ineligible for VHA care who are in need of immediate care while an appropriate permanent community placement is identified. In the current system, veterans in the community can present to VHA suicide prevention services through several different systems, including referrals to VHA and the Veterans Crisis Line (VCL). However, a portion of VCL calls are from veterans whose VHA eligibility is unknown or who are ineligible for services. If veterans are at imminent risk for suicide, emergency care is coordinated for them. However, if veterans are not at imminent suicide risk they are referred to the local suicide prevention coordinator and instructed to independently work toward determining their VHA eligibility. 
It is currently unknown how many veterans follow through with these instructions. Nonetheless, if veterans are deemed eligible, they may present to VHA to obtain a same-day appointment. If not eligible, a suicide prevention coordinator may give them the phone number of a community referral. However, this practice is not standardized across VA medical centers, and the provided resources are up to the suicide prevention coordinator to research. Additionally, when a VHA suicide prevention coordinator leaves the position, knowledge of these community resources and rapport with community HCPs are often lost, leaving the next coordinator to develop these again, which reduces the efficiency and effectiveness of limited resources. It is also unknown how many veterans complete this contact and receive evidence-based treatment following referral. This is a complex system to navigate, particularly when at risk for suicide and in need of immediate but not emergency services.

Suicide prevention in such circumstances may be improved by adapting current suicide prevention practices, including evidencebased interventions, and the new VHA intensive case management program, ${ }^{11,36}$ within a Zero Suicide framework. PSCI-SPC has developed a brief intervention to transition ineligible veterans to permanent community treatment and provide them with additional resources to meet their varied needs. The brief 1 to 3 session intervention combines practices from brief cognitive behavioral therapy (BCBT) for suicide prevention, crisis response planning (CRP), and intensive case management within a Zero Suicide framework. Both the 2019 VA/DoD suicide prevention clinical practice guidelines and Zero Suicide recommend using cognitive behavioral therapy (CBT)-based interventions for suicide prevention. ${ }^{11,32}$ These interventions are packaged into a single intervention delivered by a PSCI-SPC therapist, typically a licensed clinical social worker, a licensed clinical psychologist, or an unlicensed psychologist under the supervision of a licensed clinical psychologist.

BCBT is one type of CBT that has shown initial efficacy in reducing suicide attempts. ${ }^{37}$ BCBT reduces the risk for suicide attempts both at the conclusion of treatment and at 24-month follow-up. ${ }^{37}$
BCBT is boiled down to its most essential components so it can be delivered in a distilled format. An essential element of BCBT that will remain is the CRP. A CRP ${ }^{11,37,38}$ entails collaboratively identifying effective, appropriate coping strategies and specific individuals to contact during a crisis. CRPs demonstrated efficacy as a stand-alone intervention to existing suicide prevention methods in a randomized clinical trial, such that individuals who received CRP had faster reductions in suicidal ideation and were $76 \%$ less likely to make a suicide attempt during the 6-month follow-up period. ${ }^{39}$ These results demonstrate that use of a CRP is connected to a decrease in suicidal behavior among suicidal patients.

The VHA has developed and is piloting a new initiative focused on restructuring its intensive case management services. RACETIME to Integrated Care (eg, Risk stratification, Assessment of complexity, Coordinator of lead assignment, Evaluate whole health needs, Trusting partnerships, Integrate care, Monitor progress, Experience of the veteran and employee) is a framework that assists VHA case managers in transitioning from a traditional case management mind-set to a more integrated and holistic method of care. ${ }^{36}$ RACETIME intensive case management practices will be incorporated into the intervention. However, RACETIME focuses on case management internally to the VHA. A modification for this treatment will be to focus on intensive case management from a mental health perspective and connecting to external community resources. Community referrals are mapped within a structured process and stored on a shared drive. This improves continuity between suicide prevention coordinators when they leave for a new position.

This intervention is conducted within a Zero Suicide framework. Pertinent to PSCISPC innovation to enhance care for nonVHA veterans is the care transitions element within the Zero Suicide framework, which has developed comprehensive suicide prevention guidance, including a pathway to care. ${ }^{32}$ This pathway refers a process to conduct follow-up supportive contacts that are tracked and recorded.

The PSCI-SPC pilot program incorporates the elements of CRP and brief CBT within a Zero Suicide framework. The PSCI-SPC team 
FIGURE 2 Suicide Prevention Collaborative Program Flow

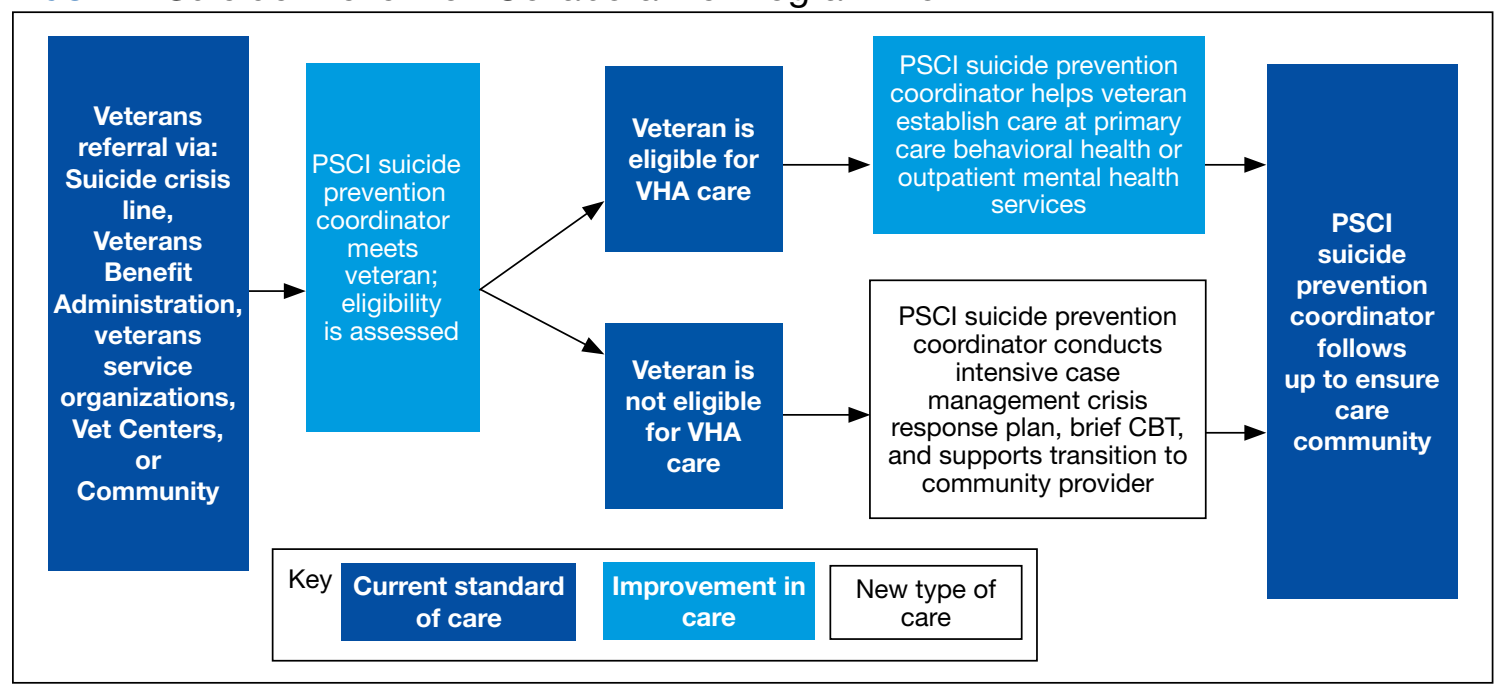

Abbreviations: CBT, cognitive behavioral therapy; PSCI, Patient Safety Centers of Inquiry; VHA Veterans Health Administration.

is developing and testing a protocol for providing brief treatment and community referrals to ineligible veterans that integrates these programming elements (Figure 2). A PSCISPC social worker will coordinate with the eligibility office to determine VHA eligibility. Ineligible veterans are referred to community partners and nonenrolled, eligible veterans are linked to VHA HCPs if they desire. These transitions will be coordinated, closely monitored, and verified. The PSCISPC team receives referrals from the VCL and other VHA programs that are in contact with ineligible veterans. Other program eligibility criteria include meeting 1 of 3 criteria: (1) a lifetime suicide attempt; (2) suicidal ideation in the past 6 months; or (3) a current mental health disorder. At the outset of the program, it is explained that the purpose of the intervention is to provide short-term, transitional services to assist the veteran in attaining a permanent mental health placement.

Once the eligibility is determined, and the veteran's preference is assessed, the team will perform a warm handoff to a VHA representative for enrollment into VHA care or to a community placement. We have sourced multiple community placements at varied payor levels. All veterans who are ineligible for care or who do not desire to be enrolled in VHA care will be provided the intervention package described above. After the veteran is placed in community care, PSCI-SPC team will follow up regularly with the veteran for 3 months to ensure continuity of care. If additional sessions are needed while the veteran needs a community placement, the PSCI team can accommodate this and will track the number of participants who needed additional sessions. If the veteran is deemed to be at imminent risk for suicide at any time during the pilot, he/she is transferred to emergency care. The veteran is allowed to participate once stabilized.

Findings from the pilot program will inform a manual intended for dissemination to patient safety and suicide prevention coordinators nationally across the VHA. The products from this objective will be integrated with the other objectives in training that will be provided on how to develop a local collaborative (Objective 1), disseminate the toolkit (Objective 2), and receive referrals into VHA or refer veterans to community clinical partners through the pilot program (Objective 3). Products developed and disseminated throughout PSCI-SPC aim to create momentum to reduce rates of suicide in veterans who are not connected to the VHA at the local community level.

\section{DISCUSSION}

Improving suicide prevention for veterans who receive non-VHA health care is essential to significantly reduce veteran suicide rates. For the past decade, VHA suicide prevention 
initiatives have largely focused on veterans eligible for care, although the fastest increase in veteran suicide rates has occurred among veterans not connected to VHA services. Currently, if a veteran is deemed ineligible for care, it is up to the veteran to find other health care services in his or her community. There is not always a clear next step for the veteran to take, nor clear guidance provided to the VHA registration staff to assist with this care transition. This is particularly concerning for veterans at high risk for suicide as this could further thwart the veteran's sense of belongingness and increase perceived burdensomeness, both suicide risk factors, and discourage them from attaining help. ${ }^{40}$ Overall, while the VHA has successfully implemented diverse suicide prevention initiatives and services, the need for continued system improvement focused on non-VHA veterans remains. PSCI-SPC was developed for this purpose.

By creating a collaborative that will connect VHA and community organizations, there will be better utilization of resources and more appropriate referrals throughout systems that interact with veterans. Sharing suicide prevention best practices between VHA and community partners is expected to increase access to mental health treatment to all veterans. Finally, by allowing best practices for suicide prevention in the VHA to serve as a guide in the development of best practices for suicide prevention between the VHA and the local health and behavioral health care community, PSCI-SPC will create a new suicide prevention intervention for veterans with mental health needs. Through these initiatives, PSCI-SPC will support providers' and concerned citizens' efforts to ensure that fewer veterans fall through the cracks of disjointed systems and will promote healthier communities where, regardless of VHA enrollment status, veterans receive suicide prevention care.

\section{CONCLUSIONS}

PSCI-SPC is a novel center for the innovation and dissemination of the nation's best practices in suicide prevention for veterans who are ineligible for or otherwise not engaged in VHA services and who turn to their community for health care. PSCI-SPC not only seeks to create, develop, and measure various solu- tions to reduce suicide among veterans who receive non-VHA care, but also seeks to facilitate the overall quality of existing practices for suicide prevention and care coordination for enrolled veterans who use community resources. By bridging the gap between the VHA, civilian health care systems, and other community partners striving to prevent veteran suicides, we can create better access to care and a more seamless path of communication among these important entities that impact the lives of our veterans daily.

\section{Author affiliations}

Bryann DeBeer is the Director of the VA Patient Safety Center of Inquiry - Suicide Prevention Collaborative and a Clinical Research Psychologist; Claire Hoffmire is an Epidemiologist and Health Science Specialist; Nathaniel Mohatt is a Research Psychologist; Germaine Franciosi is a Quality Management Specialist; Edgar Villarreal is a Clinical Psychologist and Program Manager for Suicide Prevention; all at the VA Eastern Colorado Health Care System (VAECHCS). Lindsey Monteith is a Clinical Research Psychologist; Dawn Pierson is a Program Specialist; and Samantha Synett is Suicide Prevention Coordinator; all at the Rocky Mountain Mental Illness, Research, Education and Clinical Center (MIRECC) for Suicide Prevention, Rocky Mountain Regional Veterans Administration Medical Center in Aurora, Colorado. Bryann DeBeer is a Visiting Associate Professor; Claire Hoffmire is an Assistant Professor; and Nathaniel Mohatt is an Assistant Professor in the Department of Physical Medicine and Rehabilitation; Lindsey Monteith is an Associate Professor in the Department of Psychiatry; all at the University of Colorado Anschutz Medical Campus in Aurora, Colorado. Joseph Mignogna is a Clinical Research Psychologist; and Justin Benzer is the Implementation Core Chief; both at the VA VISN 17 Center of Excellence for Research on Returning War Veterans in Waco and the Central Texas Veterans Health Care System. Sylvia Baack is the Director of Quality, Safety, and Value; Kathryn Bongiovanni and Kattina Bryant are Suicide Prevention Coordinators; Stephanie Clafferty and Kimberly Weinberg are Social Work Supervisors; Marjory Williams is the Associate Chief Nurse, Research; all at the Central Texas Veterans Health Care System in Waco, Temple, and Austin. Elisa Borah is the Director of the Institute for Military and Veteran Family Wellness and a Research Associate Professor at the Steve Hicks School of Social Work at the University of Texas at Austin. Craig Bryan is the Stress, Trauma, and Resilience (STAR) Professor at The Ohio State University Wexner Medical Center in Columbus. Ruth Cassidy is the Navy Suicide Prevention Program Manager/Lead Analyst in the 21st Century Sailor Office, Compliance and Competencies Branch in the US Navy, Millington, Tennessee. Jenna Heise is Texas State Suicide Prevention Coordinator in the Office of Mental Health Coordination, Suicide Prevention Team, Health and Human Services Commission in Austin and Zero Suicide Faculty at Zero Suicide Institute, Education Development Center in Waltham, Massachusetts. Robin Keene is not affiliated with an organization. Joseph Mignogna is an Adjunct Assistant Professor in the Department of Psychiatry and Behavioral Sciences at the College of Medicine, in Temple, Texas. Alan Peterson is a Professor in the Department of Psychiatry and Behavioral Sciences, University of Texas Health Science Center at San Antonio; a Research Health Scientist in the Research and Development Service, South Texas Veterans Health Care System; and a Professor in the Department of Psychology, University of Texas at San Antonio. Nathaniel Mohatt is a Clinical Instructor in the Division of Prevention and Community Research, Department of Psychiatry, Yale School of Medicine. Justin Benzer is an Associate Professor in the Department of Psychiatry, Dell Medical School, University of Texas at Austin. 


\section{Author disclosures}

The authors report no actual or potential conflicts of interest with regard to this article. This work was supported by a Patient Safety Center of Inquiry Grant from the Department of Veterans Affairs National Center for Patient Safety.

\section{Disclaimer}

The opinions expressed herein are those of the authors and do not necessarily reflect those of Federal Practitioner, Frontline Medical Communications Inc., the US Government, any of its agencies, or any other affiliates.

\section{References}

1. US Department of Veterans Affairs. National strategy for preventing veteran suicide 2018-2028. https://www .mentalhealth.va.gov/suicide_prevention/docs/Office-of -Mental-Health-and-Suicide-Prevention-National-Strategy -for-Preventing-Veterans-Suicide.pdf. Published September 2018. Accessed October 14, 2020.

2. US Department of Veterans Affairs, Office of Mental Health and Suicide Prevention. National veteran suicide prevention annual report. https://www.mentalhealth.va.gov /suicide_prevention/data.asp. Accessed October 14, 2020.

3. Centers for Disease Control and Prevention. Web-based injury statistics query and reporting system (WISQARS). 2014. https://www.cdc.gov/injury/wisqars/index.html. Updated July 1, 2020. Accessed October 14, 2020.

4. Lemle RB. Choice program expansion jeopardizes high-quality VHA mental health services. Fed Pract. 2018;35(3):18-24.

5. US Department of Veterans Affairs, Office of Mental Health and Suicide Prevention. VA national suicide data report 2005-2016. https://www.mentalhealth.va.gov /docs/data-sheets/OMHSP National Suicide Data Report 2005-2016 508.pdf. Published September 2018. Accessed October 14, 2020.

6. US Department of Veterans Affairs, Office of Suicide Prevention. VA national suicide data report 2005-2015. https://www.mentalhealth.va.gov/docs /data-sheets/2015/OMHSP_National_Suicide_Data _Report_2005-2015_06-14-18_508.pdf. Published June 2018. Accessed October 14, 2020.

7. US Department of Veterans Affairs. National strategy for preventing veteran suicide 2018-2028. https://www. mentalhealth.va.gov/suicide_prevention/docs/Office-of -Mental-Health-and-Suicide-Prevention-National-Strategy -for-Preventing-Veterans-Suicide.pdf. Published 2018. Accessed October 30, 2020.

8. Gordon RS. An operational classification of disease prevention. Public Health Rep. 1983;98(2):107-109.

9. National Research Council and Institute of Medicine. O'Connell ME, Boat T, Warner KE, eds. Preventing Mental, Emotional, and Behavioral Disorders Among Young People: Progress and Possibilities. Washington, DC: National Academies Press; 2009.

10. US Department of Health and Human Services, National Institute on Drug Abuse, Office of Science Policy and Communications. Drug Abuse Prevention: What Works. Rockville, MD: National Institutes of Health; 1997.

11. US Department of Veterans Affairs, US Department of Defense. VAVDoD clinical practice guideline for the assessment and management of patients at risk for suicide. https:// www.healthquality.va.gov/guidelines/MH/srb. Published 2019. Updated July 30, 2020. Accessed October 14, 2020.

12. US Department of Veterans Affairs. Veterans Access, Choice and Accountability Act of 2014. https:// wWw.govinfo.gov/content/pkg/PLAW-113publ146/pdf /PLAW-113publ146.pdf. Accessed October 14, 2020.

13. US Department of Veterans Affairs. Strategic Health Care. VA MISSION Act: Extension of the VA choice program. https://strategichealthcare.net/wp-content /uploads/2018/05/052718-VA-MISSION-Act-Summary.pdf. Accessed October 14, 2020.

14. US Congress. H.R.5674-VA MISSION Act of 2018. https://www.congress.gov/bill/115th-congress/house -bill/5674. Accessed October 15, 2020.

15. Grumet JG, Hogan MF, Chu A, Covington DW, Johnson $\mathrm{KE}$. Compliance standards pave the way for reducing suicide in health care systems. J Health Care Compliance. 2019;17-26.

16. Hillestad R, Bigelow J, Bower A, et al. Can electronic medical record systems transform health care? Potential health benefits, savings, and costs. Health Aff (Millwood). 2005;24(5):1103-1117. doi:10.1377/hlthaff.24.5.110

17. Porter ME, Pabo EA, Lee TH. Redesigning primary care: a strategic vision to improve value by organizing around patients' needs. Health Aff (Millwood). 2013;32(3):516-525. doi:10.1377/hlthaff.2012.0961

18. Nevedal AL, Wagner TH, Ellerbe LS, Asch SM, Koenig CJ. A qualitative study of primary care providers' experiences with the Veterans Choice Program. J Gen Intern Med. 2019;34:598-603. doi:10.1007/s11606-018-4810-2

19. Tanielian T, Farris C, Epley C, et al. Ready to serve: community-based provider capacity to deliver culturally competent, quality mental health care to veterans and their families. https://www.rand.org/content/dam/rand/pubs /research_reports/RR800/RR806/RAND_RR806.pdf. Published 2014. Accessed October 15, 2020.

20. White House. Executive Order 13861: President's roadmap to empower veterans and end the national tragedy of suicide (PREVENTS). https://www.va.gov/PREVENTS /docs/PRE-007-The-PREVENTS-Roadmap-1-2_508.pdf. Published June 17, 2020. Accessed October 15, 2020.

21. US Department of Veterans Affairs, Office of the Under Secretary for Health. Memorandum. VA continues community suicide prevention challenge at another mayor's challenge policy academy. https://www.blogs.va.gov NAntage/58468/va-continues-community-suicide-preven tion-challenge-another-mayors-challenge-policy-academy. Published April 4, 2019. Accessed October 15, 2020.

22. US Department of Veterans Affairs, Veterans Health Administration (VHA) Veterans Health Administration (VHA) Fiscal Year (FY) 2018-2019 Operational Plan. www.navao .org/wp-content/uploads/2018/06/USH-Memo-10-2018 -03-VHA_FY_2018-2019_Operational_Plan-4-19-18.pdf. Published April 19, 2018. Accessed October 15, 2020.

23. US Department of Veterans Affairs. VA, Health and Human Services announce governor's challenge to prevent suicide. https://www.blogs.va.gov/VAntage/55707/va-health -human-services-announce-governors-challenge-prevent -suicide. Published January 17, 2019. Accessed October 15, 2020.

24. VA's suicide prevention campaign "Be There" kicks off in Times Square. https://www.blogs.va.gov/VAntage/57272 /vas-suicide-prevention-campaign-kicks-off-times-square. Published March 6, 2019. Accessed October 15, 2020.

25. US Department of Veterans Affairs, Office of Public Affairs Media Relations. Emergent mental health care for former service members. https://www.mentalhealth.va.gov/docs /Fact_Sheet-Emergent_Mental_Health_Care_Former Service_Members.pdf. Published 2017. Accessed October 15,2020

26. US Department of Veterans Affairs. VA secretary formalizes expansion of emergency mental health care to former service members with other-than-honorable discharges. https://www.blogs.va.gov/VAntage/39092/va-secretary -formalizes-expansion-emergency-mental-health-care -former-service-members-honorable-discharges. Published June 27, 2017. Accessed October 15, 2020.

27. Shane L. New veteran suicide numbers raise concerns among experts hoping for positive news. Military Times. https://www.militarytimes.com/news/pentagon -congress/2019/10/09/new-veteran-suicide-numbers -raise-concerns-among-experts-hoping-for-positive-news. Published October 9, 2019. Accessed October 15, 2020.

28. US Department of Veterans Affairs. Department of Veterans Affairs FY 2018-2024 Strategic Plan. https://www.va.gov /oei/docs/VA2018-2024strategicPlan.pdf. Updated May 31, 2019. Accessed October 15, 2020.

29. Komaie G, Goodman M, McCall A, et al. Training community members in public health research: develop- 
ment and implementation of a community participatory research pilot project. Health Equity. 2018;2(1):282-287. doi:10.1089/heq.2018.0043

30. Wang KH, Ray NJ, Berg DN, et al. Using community-based participatory research and organizational diagnosis to characterize relationships between community leaders and academic researchers. Prev Med Reports. 2017;7:180-186. doi:10.1016/j.pmedr.2017.06.007

31. Institute for Healthcare Improvement. The breakthrough series: IHI's collaborative model for achieving breakthrough improvement. http://www.ihi.org/resources/Pages /IHIWhitePapers/TheBreakthroughSeriesIHIsCollabora tiveModelforAchievingBreakthroughlmprovement.aspx. Published 2003. Accessed October 15, 2020.

32. Zero Suicide in Health and Behavioral Health Care Institute. Zero suicide toolkit. https://zerosuicide.sprc.org/toolkit. Accessed October 15, 2020.

33. Preventing suicide: a technical package of policy, programs, and practices. https://www.cdc.gov/violencepre vention/pdf/suicideTechnicalPackage.pdf. Published 2017. Accessed October 30, 2020.

34. US Department of Veterans Affairs. VA Office of Mental Health and Suicide Prevention guidebook. https://www mentalhealth.va.gov/docs/VA-Office-of-Mental-Health-and -Suicide-Prevention-Guidebook-June-2018-FINAL-508.pdf Published June 2018. Accessed October 15, 2020.

35. US Department of Health and Human Services, Substance Abuse and Mental Health Services, Administration Center for Substance Abuse Prevention. Focus on prevention: strategies and programs to prevent substance abuse. HHS Publication No. (SMA) 10-4120. https://helpandhopewv .org/docs/Focus\%20on\%20Prevention.pdf. Revised 2017. Accessed October 15, 2020.

36. Misiti R, Risinger A. RACETIME: an organizational care coordination approach to improving patient outcomes in a complex healthcare setting. Presentation at the Military Social Work \& Behavioral Health Conference Austin, Texas. July 23, 2020. https://sites.utexas.edu/military-social-work -conference/misiti-risinger. Accessed October 23, 2020.

37. Rudd MD, Bryan CJ, Wertenberger EG, et al. Brief cognitive-behavioral therapy effects on post-treatment suicide attempts in a military sample: results of a randomized clinical trial with 2-year follow-up. Am J Psychiatry. 2015;172(5):441-449. doi:10.1176/appi.ajp.2014.14070843

38. Rudd MD, Mandrusiak M, Joiner TE Jr. The case against no-suicide contracts: The commitment to treatment statement as a practice alternative. Clin Psychol. 2006;62(2):243-251.

39. Bryan CJ, Mintz J, Clemans TA, et al. Effect of crisis response planning vs. contracts for safety on suicide risk in US Army soldiers: a randomized clinical trial. J Affect Disord. 2017;212:64-72. doi:10.1016/j.jad.2017.01.028

40. Joiner TE. Why People Die by Suicide. Cambridge, MA: First Harvard University Press; 2005:27.

41. Office of the Under Secretary of Defense for Personnel and Readiness. DoD Instruction 6490.16: Defense sui- cide prevention program. https://www.esd.whs.mil /Portals/54/Documents/DD/issuances/dodi/649016p .pdf?ver=2020-09-11-122632-850. Published November 6, 2017. Updated September 11, 2020. Accessed October 14, 2020.

42. Zero Suicide in Health and Behavioral Health Care Institute. Engage: engaging patients. http://zerosuicide.edc.org /toolkit/engage\#quicktabs-engage $=0$. Accessed October $14,2020$.

43. Stone D, Holland K, Bartholow B, Crosby A, Davis S, Wilkins N. Preventing Suicide: A technical package of policy, programs, and practices. https://www.cdc.gov /violenceprevention/pdf/suicidetechnicalpackage.pdf. Published 2017. Accessed October 14, 2020.

44. Mills PD, Watts BV, Miller S, et al. A checklist to identify inpatient suicide hazards in veterans affairs hospitals. Jt Comm J Qual Patient Saf. 2010;36(2):87-93. doi:10.1016/s1553-7250(10)36015-6

45. US Department of Veterans Affairs, Office of Research and Development. Crisis prevention: study evaluates VA program that identifies vets at highest risk for suicide. https://www .research.va.gov/currents/0918-Study-evaluates-VA -program-that-identifies-Vets-at-highest-risk-for-suicide.cfm. Updated September, 20, 2018. Accessed October 14, 2020.

46. Zero Suicide in Health and Behavioral Health Care Institute. Engage: active engagement for safer suicide care-reducing access to lethal means. http://zerosuicide.edc .org/toolkit/engage\#quicktabs-engage=1. Published 2017. Accessed October 14, 2020.

47. Zero Suicide in Health and Behavioral Health Care Institute. Train: training for all. http://zerosuicide.sprc.org/toolkit/train. Accessed October 14, 2020.

48. US Department of Veterans Affairs, Office of Mental Health and Suicide Prevention (OMHSP). Facts about veteran suicide. https://www.mentalhealth.va.gov/docs/FINAL VA _OMHSP_Suicide_Prevention_Fact_Sheet_508.pdf. Published June 2018. Accessed October 14, 2020.

49. Zero Suicide in Health and Behavioral Health Care Institute. Treat: direct treatment. http://zerosuicide.edc.org/toolkit /treat. Accessed October 14, 2020.

50. Office of the Under Secretary of Defense for Personnel and Readiness. DoD Instruction 6490.04: Mental health evaluations of members of the military services. https:// www.esd.whs.mil/Portals/54/Documents/DD/issuances /dodi/649004p.pdf. Published March 4, 2013. Updated April 22, 2020. Accessed October 14, 2020.

51. US Department of Veterans Affairs, Office of Mental Health and Suicide Prevention Frequently asked questions: VA National Suicide Data Report. https://www.mentalhealth .va.gov/docs/data-sheets/2015_Data_Release_FAQs_508 .pdf. Published September 2018. Updated June 22, 2018. Accessed October 14, 2020.

52. Zero Suicide in Health and Behavioral Health Care Institute. ZERO Suicide engage: active engagement for safer suicide care safety planning. http://zerosuicide.edc.org/toolkit lengage\#quicktabs-engage=1. Accessed October 14, 2020. 